\title{
DIREITO COMERCIAL E DESENVOLVIMENTO ECONÔMICO
}

\author{
COMMERCIAL LAW AND ECONOMIC DEVELOPMENT
}

Recebido: 06.11.2017

Aprovado: 08.11.2017

Rachel Sztajn*

RESUMO: O texto pretende contribuir para a discussão relacionada ao desenvolvimento econômico e o papel ou função de normas jurídicas e/ou sociais. A denominada lex mercatoria, fruto da necessidade de afastar a aplicação do direito comum, criou regras especiais que, aplicadas pelas corporações, geraram confiança e estímulos para o exercício da atividade. Quanto à questão da codificação desse ramo do Direito, estudo de Lisa Bernstein, explica não ser a solução ideal enquanto o de Schäfer e Wulf se volta para a importância da formação de profissionais do direito para dar segurança aos agentes econômicos em suas relações econômicas. A conclusão do texto é de que, sem confiança não haverá investimentos produtivos e que, dessa forma, a legislação, seja a positivada ou a soft Law é essencial para o crescimento econômico.

Palavras-chave: Comercial. Desenvolvimento econômico. Relações Econômicas.

ABSTRACT: The study aims to contribute to the discussion of economic develpment/ growth and the Law. Startig with the lex mercatória, the discussion goes back to the Middle Age and the contribution of merchants to the development. Reference is made to Bernstein and Schäfer-Wuld studies to demonstrate that codes are not Always necessary but scientifically prepared professional are mandatory. But mainly that with no confidence in the institutions, no investment decisions will be made, harming the society in general.

Keywords: Commercial. Economic development. Economic Relations.

* Professora Associada de Direito Comercial da Faculdade de Direito da Universidade de São Paulo. Doutora em Direito pela Universidade de São Paulo. E-mail: < rasztajn@gmail.com >. 


\section{INTRODUÇÃO}

Nada obstante o texto priorize o direito comercial, reconhecer a importância de normas, tenham elas suporte no direito positivo ou sejam produto práticas sociais, sua importância e acatamento tem como efeito direto aumentar a segurança das pessoas na tomada de decisões.

Também não se pretende discutir o monismo ou dualismo do direito privado no que concerne à delimitação da área de incidência das normas especiais, as de direito comercial/empresarial, proposta e ao depois rejeitada por Cesare Vivante. Mesmo porque Sylvio Marcondes explicou que a dicotomia do direito privado não constitui embaraço para a coordenação entre as duas áreas, como se dá em alguns países, notadamente no que diz respeito à unificação do direito das obrigações.

Premissa para o ensaio é a dinâmica das atividades econômicas que, mesmo em comunidades/ sociedades menos desenvolvidas levou ao surgimento de instituições sociais que privilegiaram a segurança das operações econômicas nas comunidades. Tais instituições sociais, entendidas como as "regras do jogo", na dicção de Douglas North ao comparar o desenvolvimento econômico de países, tornam-se, quando recepcionadas pelo direito positivo, institutos de direito posto.

A qualidade de recepção das instituições sociais, que devem ser entendidas como mecanismos de estímulos - positivos ou negativos, que Norberto Bobbio define como função promocional do Direito - na sua conversão em institutos jurídicos é fator impactante do resultado. Se a recepção deixa de lado algum incentivo socialmente desejável, o resultado tenderá a ser ruim. Bem assim se a norma positivada engessar a criatividade humana, de alguma forma bloquear inovações, o resultado ou efeito de segunda ordem como explicam os economistas, será igualmente indesejável.

Sob esta perspectiva, o Direito Comercial, ao disciplinar as atividades econômicas exercidas profissionalmente, nas quais a troca de bens e a prestação de certos serviços, ou a transformação de bens (insumos) para em seguida, oferta-los em mercados, visando, precipuamente, a obter ganhos mediante a satisfação de necessidades ou desejos de pessoas ou comunidades. Aqui a importância das normas de Direito Comercial ao não impedir ganhos (lucros), geração de riqueza e bem-estar, para o desenvolvimento econômico das sociedades.

\section{ASPECTOS HISTÓRICOS}

A busca de bens desejados pelas pessoas e não existentes ou produzidos nas suas comunidades, estimula a atividade de intermediação e sua profissionalização mediante busca desses bens existentes ou produzidos em outros locais. Inicialmente isso era feito por meio do deslocamento dos mercadores, o que era facilitado em cidades portuárias como, por exemplo, Gênova e Veneza, cidades do norte da Itália, mas com acesso ao Mar Mediterrâneo.

Mercadores italianos, sem esquecer os chineses que, muito antes, exerciam atividades comerciais na Ásia, aproveitando as facilidades do transporte marítimo, fazem das cidades portuárias importantes centros comerciais. Florença, cidade não costeira, só 
ganha importância econômica com sob o comando da família Medici, tornando-se outro centro de criação de riqueza.

Sabe-se que o poder conquistado e exercido por essa família resultou de estratégias bem urdidas e implementadas. A par de se fortalecerem politica e economicamente os Medici apoiaram artistas legando à cidade de Florença, um conjunto de belíssimas obras de arte entre as quais pinturas e esculturas, que podem ser considerados uma espécie de investimento cultural que também atrai riqueza por meio de visitantes.

Fácil compreender a influência do transporte marítimo no incentivo ao crescimento das cidades portuárias, o que, não significou que os mercadores sempre viajassem em busca dos bens que comerciavam. Aos poucos emerge tendência para o sedentarismo, transferindo para terceiros o mister de efetuar a busca e o transporte dos bens que negociavam. $\mathrm{O}$ comerciante que ia às feiras e arcava com os custos de transporte, riscos e dificuldades com a infraestrutura, desaparece sendo substituído pelo comerciante sedentário.

O processo de crescimento da atividade de intermediação na circulação da riqueza (mercadorias) pode ser entendido como uma revolução comercial, amplificado com a criação da Bolsa, na Holanda, além do aumento das relações entre os Países Baixos ea Grã-Bretanha, do surgimento de instituições para facilitar o câmbio de moedas entre as diferentes cidades, numa espécie de globalização capitalista pré-industrial.

A isso se somam instituições como a Liga Hanseática, organização que defendia interesses das guildas mercantis, a atuava como facilitadora da dispersão do comércio ao longo dos mares do Norte e Báltico, chegando a cidades como Bergen, Bruges, Novogorod, por exemplo. Isto permitiu que mercadores do norte da Alemanha intermediassem trocas de bens como grãos, peles, entre outros, entre o Báltico e a Alemanha, Flandres, Inglaterra e Escandinávia.

O transporte, que mantém sua função história de abastecimento de bens em diversos mercados, por força dos riscos gerados por atos de pirataria ou saques, leva à criação de instrumento de garantia contra perdas disso decorrentes, o seguro. Quanto ao transporte de valores em espécie, entre os quais metais raros, a solução deu-se com a criação dos títulos de crédito; já para fins de reunião de recursos para investimento na atividade comercial, modelam-se estruturas associativas visando a facilitação no agregar investidores que aceitassem a especulação mercantil visando a obter ganhos se o empreendimento conjunto fosse bem sucedido.

Os nobres que controlavam as cidades em que eram realizadas as feiras ofereciam segurança o que gerava confiança entre os comerciantes para delas participarem.

\section{INOVAÇÕES E PRÁTICAS COMERCIAIS}

Como exposto acima, a criatividade dos agentes econômicos tinha como escopo facilitar as atividades e minorar, na medida do possível, os riscos a que teriam de considerar (ou precificar).

Os títulos de crédito, de que a letra de câmbio ou lettera di pagamento di cambio, é a primeira espécie, são fruto tanto dos riscos de circulação de bens físicos como ouro 
entre cidades-estados, na baixa Idade Média, quanto da eventual dificuldade em fazer pagamentos com moedas da cidade de origem do comerciante em outra(s) praça(s), uma vez que cada governo tinha o poder para emitir/cunhar sua própria moeda, a de curso forçado. Assim, a necessidade do câmbio - troca entre moedas usadas por pessoas residentes em diferentes cidades, incentivou banqueiros a, entre si, ajustarem regras que disciplinassem o processo de troca de moedas de diferentes denominações. Daí as letras de câmbio, documento emitido por um banqueiro contra o recebimento de recursos e que seria aceito banqueiro de outra cidade que entregaria ao portador nomeado no documento, moeda daquela cidade.

Esses procedimentos - emissão da letra de câmbio pelo banqueiro da cidade $\mathrm{A}$ contra o recebimento da moeda ali em circulação, e sua reconversão pelo banqueiro da cidade $\mathrm{B}$ na moeda desta cidade, solucionava necessidades de comerciantes de terem moeda da cidade em que se abasteceriam e evitava que viajassem com metais preciosos. Genial criação de banqueiros/comerciantes que, na linguagem econômica, reduz custos de transação e facilita o exercício da mercancia entre agentes que operam em diferentes cidades.

Foi, igualmente, criada a denominada conta corrente mercantil, em que cada banqueiro lançava o montante das trocas de moeda lastreadas nas letras de câmbio e, periodicamente, apurava-se o saldo dessas operações que eram compensadas (débitos e créditos recíprocos) durante o lapso temporal acordado. O saldo líquido era computado como débito de um e crédito do outro devendo ser liquidado.

Ideada no norte da Itália, a letra de câmbio era, já no Século XIV, largamente utilizada em outras regiões da Europa, pois facilitava a circulação de "moeda". Seria, talvez, equiparável, à moeda escritural embora com lastro real.

A confiança na circulação do crédito, notadamente quando representado por esses títulos, facilitava a aproximação entre doadores e tomadores de recursos financeiros, tanto é que a concessão de empréstimos por banqueiros florentinos demonstra a importância dessa atividade para o desenvolvimento da economia.

Também no que tange aos riscos marítimos, começam a ser garantidos por uma operação similar ao seguro que se pratica atualmente, conquanto não fundada em cálculo atuarial ou matematização do risco, como dizem alguns.

Estruturas societárias como a "comenda", ou sociedade em comandita, em que havia sócios ostensivos e ocultos, permitia que fossem contornadas proibições quanto ao exercício do comércio por pessoas pertencentes a algumas classes sociais, entre elas nobres e clérigos, que gostariam de auferir lucros mas não podiam exercer o comércio. A estrutura societária da sociedade em comandita facilitava a contribuição de recursos em troca de futura partilha dos resultados - ganhos - ao mesmo tempo que limitavam as perdas ao montante investido, sem que terceiros tivessem informação da participação dessas pessoas, sócias ocultas, no empreendimento que era administrado pelo(s) sócio(s) ostensivo(s).

Tullio Ascarelli explica que a proibição da realização de alguma operação que interesse às pessoas, leva à inovação mediante o recurso a outro(s) instrumentos 
negociais que produzam o fim desejado, por ele denominado de negócio indireto. Mark Roe, igualmente, considera que as pessoas - agentes econômicos - buscam brechas nas normas para obterem, a custos menores, resultados que as interessem.

Dessa perspectiva a cultura mercantilista desde a baixa Idade Média, é pródiga na criação de instituições sociais, regras cujo escopo é, sempre, facilitar operações mercantis de sorte a estimular a circulação de mercadorias mediante arbitramento de preços; quanto ao crédito, fator necessário para o desenvolvimento da atividade, o tema segurança se revela decisivo com a bancarrota, ou falência, que retirava do mercado agentes cujo patrimônio ativo era inferior ao passivo e que, por isso representavam risco para os credores.

A bancarrota, quebra da banca (mesa de operações do banqueiro) eliminava do mercado de crédito aqueles que tivessem tomado mais riscos nos empréstimos do que a prudência recomendaria. Há quem associa os bancos de investimento, instituições que financiam demandas de recursos de longo prazo, aos comerciantes que faziam o transporte de mercadorias, afirmando que os bancos de investimento espelham práticas do período medieval quanto a empréstimo de recursos para pagamento no longo prazo. Claro que ao longo do tempo novas e complexas operações, e regulação do sistema financeiro foram estruturadas, notadamente no século XX.

Quanto aos títulos de crédito que representam o direito de receber o montante expresso no documento, a coobrigação de terceiros que tenham de alguma forma participado do processo de circulação do documento ou prestado garantia, particularmente no caso de instrumentos nominativos não à ordem, constitui outra forma de gerar confiança entre os integrantes da cadeia circulatória.

A prática de comerciantes da região da Toscana de relacionarem os bens familiares e a forma pela qual eram administrados, a existência de documentos referentes a regras de práticas comerciais, com informações úteis aos comerciantes - rotas, distâncias, moedas locais, pesos e medidas, especiarias, impostos e tarifas, frete, ilumina a influência das práticas na atividade e no sistema econômico.

Há quem associe a noção de grupo econômico a práticas dos mercadores italianos no que se conhece como sistema di aziende, espécie de organização multinacional e com administração hierárquica, em que diferentes atividades estavam presentes numa cadeia societária, clara demonstração da pujança da economia no período medieval.

\section{DIREITO E COMÉRCIO}

Estudo dos professores Hans-Bernd Schäfer e Alexander J. Wulf, ${ }^{,}$, institulado Jurists, Clerics and Merchants, associa o desenvolvimento econômico na Europa, no período entre 1200 e 1600 , à criação em diversas cidades, de faculdades de Direito. Entendem que a recepção do direito romano, que passou a ser ensinado na academia, formava profissionais de modo sistemático e cientifico, o que conferia maior segurança aos agentes econômicos ao contarem com a assessoria de especialistas, o que lhes

1 Disponível em: < SSRN.com >. 
dava maior segurança na celebração de contratos, com o consequente estímulo para o surgimento e/ou crescimento do comércio e, portanto, de ganhos econômicos nessas cidades.

Concluem os autores que o desenvolvimento de novas habilidades por esses profissionais do Direito, colaborou para o crescimento do comércio, mesmo reconhecendo que o impacto da adoção do direito romano sobre a população em geral fosse marginal. Atividades econômicas eram atraídas para regiões próximas das Faculdades de Direito, o que, entendem, resultou da cientificidade, racionalidade e sistematização que o ensino do Direito produziu.

Veja-se, a propósito, a conclusão do texto: Our study supports conjectures of legal historians, especially Wieacker, Greiff, Behrman, and Whitman that the medieval economic rise of Europe owes much to the rise of law to a scholarly discipline and to an autonomous system.

Mesmo sem especificar que a formação dos profissionais do Direito seria voltada para o comércio, fica patente que o ensino sistemático da disciplina, provavelmente questões relacionadas à circulação da propriedade - direito das obrigações e contratos aumentava a confiança dos agentes econômicos, gerava riqueza e bem-estar.

$\mathrm{O}$ estudo não afasta a aplicação de regras contempladas na denominada lex mercatoria, enfatizando, tão somente, a atração de negócios para as cidades em que se sabia haver profissionais aptos a, cientificamente, analisar operações, assessorar na celebração de contratos bem assim magistrados igualmente formados para analisar e aplicar regras jurídicas a eventuais disputas.

Não se deve confundir a expressão lex mercatoria com alguma forma de codificação normas regentes das atividades comerciais na Idade Média. O comércio, na época, era regido por práticas - usos e costumes - e as disputas eram submetidas a tribunais especializados com domínio sobre os procedimentos comerciais e não às cortes ordinárias.

Paulatinamente as práticas comerciais tendem à universalidade e uniformização, o que se acentua na atualidade dada a globalização, uma espécie de reconhecimento do que teria ocorrido na Idade Média a fim de dar segurança aos operadores econômicos.

A semelhança com o que se tem hoje em relação a UNCITRAL, OMC, entre outros que, reunindo representantes de inúmeros países, propõem regras para a disciplina de atividades econômicas, regras essas que podem, ou não, ser objeto de promulgação pelos países signatários.

De toda sorte a confiança é fator predominante para o comércio, particularmente quanto à decisão de investir, pondo em destaque a ética que se tende a associar a preceitos religiosos. Será razoável ligar o mercantilismo, origem do capitalismo atrás referido, invocando práticas ou credos religiosos e não apenas a regras jurídicas? Se confiança é fator primordial para o funcionamento da econômica, em que medida preceitos religiosos auxiliam na criação de confiança entre pessoas de uma comunidade, sem o que não há desenvolvimento do comércio?

Normas jurídicas facilitam o comercio entre pessoas que não seconhecem, situação 
cada vez mais frequente na atualidade em que a prosperidade exige especialização, que de sua parte depende de confiança para que se alcance a desejada coordenação afastando oportunismos. Exemplo simples é o do quid pro quo em que as prestações não são simultâneas. Este o espaço em que normas jurídicas e religiosas podem, harmonicamente, ampliar os níveis de confiança recíproca.

Não haverá desenvolvimento sem organização econômica eficienteo que se associa a arranjos institucionais e clara definição de direito de propriedade para incentivar o direcionamento dos esforços individuais para as atividades econômicas criando retornos tanto individuais quanto coletivos, conforme ensina Douglas North, ou seja, sem clara definição de direitos e cumprimento de contratos, faltarão os comerciantes segurança e previsibilidade para se engajarem em projetos econômicos de longo prazo.

Dessa ótica instituições comerciais, mesmo que sejam qualificadas como soft Law, similares à denominada lex mercatoria, estimulam a criação de riqueza e levam à prosperidade social. A religião se relaciona à prosperidade na medida em que instituições sociais incorporem valores como ética, mérito do empreendedor. Paralelamente as redes sociais e/ou religiosas colaboram com o ambiente econômico-mercantil ao criarem confiança atuando como supletivas das normas legais no que diz respeito a direitos e obrigações, notadamente porque o comércio requer, dos agentes econômicos, comportamentos moralmente desejáveis.

Da perspectiva econômica a importância da lei está em estimular o comércio com segurança. Já a religião tende a priorizar as pessoas e suas relações sociais prevalecem sobre as materiais. A estratégia religiosa para gerar confiança resulta dos vínculos estabelecidos entre as comunidades que professam o mesmo credo, o que afasta a ideia de estranhos envolvidos em atividades comerciais. Destarte leis e religião podem criar a confiança necessária dentro do espectro social para que haja crescimento econômico e prosperidade social.

Discussão usual tem a ver com a proibição religiosa da usura, vista como pecado, como se as pessoas devessem ser mutuamente solidárias na tomada de risco inerente às operações mercantis, quando não a incertezas. E como explicar custos de oportunidade que, igualmente, afetam a precificação do dinheiro? Respostas a essas questões levam à conclusão de que será legítima a remuneração do doador de recursos (quem poupa), cabendo ao devedor arcar com esse ônus. Entende-se que dinheiro investido é bem produtivo enquanto o entesourado é estéril. O que não se aceita, social e religiosamente, são cobranças que extraiam bem estar dos devedores.

A discussão sobre abusividade dos juros cobrados impacta a oferta por crédito mercantil e abre espaço para práticas opacas na definição da taxa de juros e do preço dos serviços cobrados dos tomadores de recursos, o que hoje se conhece como shadow banking.

Outro elemento que impacta a oferta de crédito e o preço dos serviços financeiros, no Brasil, tem origem em decisões judiciais uma das quais, a do adimplemento substancial de contratos de financiamento - em geral contratos de longo prazo e execução continuada - incompletos por natureza dada a inviabilidade de se prever todos e quaisquer eventos 
futuros que possam impactar a prestação do devedor. Ao decidir que se parte relevante do financiamento foi adimplida, isenta-se o devedor do pagamento do saldo o que tende a aumentar os custos de financiamento para potenciais tomadores no futuro. Melhor, parece-me, seria retomar a noção de que dinheiro ocioso, entesourado, é estéril e, portanto danoso para a economia. Vale notar que os valores emprestados pelos integrantes do sistema financeiro não são parte do capital social mas resultam de aplicações e depósitos feitos por terceiros que têm direito de receber o que aplicaram/depositaram.

\section{DIREITO POSITIVO V. USOS E COSTUMES}

Lisa Bernstein, em artigo, denominado Merchant Law in a Modern Economy², discute a proposta de seu adotar, nos Estados Unidos da América, um Código Comercial, o Uniform Commercial Code, alternativa que não prosperou. Lembre-se que naquele pais a maior parte das normas jurídicas é estadual e, muitas vezes, a escolha de uma jurisdição serve como sinalizador para o mercado. Exemplo é a adoção de Delaware como sede de muitas companhias pois a existência de um Tribunal especializado em discussões societárias indica aos investidores que os administradores poderão ser punidos de agirem de forma negligente ou imprudente que imponha perdas à sociedade.

A ênfase de Bernstein recai sobre usos e costumes na interpretação dos contratos mercantis pelos Tribunais, apontando que a intenção do autor do Código, Karl LLewellyn foi prover normas supletivas e simplificar, iluminar e atualizar as leis que regem os contratos comerciais. A ênfase nos usos e costumes destina-se a facilitar a expansão das práticas mercantis, de sorte que normas codificadas sejam adaptadas a novas e imprevisíveis práticas e circunstâncias sem necessidade de reformas legislativas.

A conclusão da autora é no sentido de ser pouco provável que a proposta de código venha a atender as demandas da economia moderna. Parece propensa a preservar os usos e costumes que melhor servem à dinâmica do comércio.

A resposta de Bernstein referente à existência de usos e costumes mercantis pode ser encontrada no direito comercial medieval, acima comentado, ainda que se questione ter havido, efetivamente, conjunto de normas não escritas relacionadas a costumes mercantis na lex mercatoria. Recorrer a instrumentos contratuais escritos, ainda que padronizados, é mais simples.

As conclusões de Bernstein facilitam tratar da necessidade, ou não, de um código comercial. Lembrando Natalino Irti que, em L'età della decodificazione’3, defendeu que os códigos perderam o papel de núcleos do sistema jurídico após a promulgação das atuais Constituições.

A par disso, a dinâmica e crescente complexidade da atividade comercial, requer a aceitação de usos e costumes, isto é, práticas inovadoras que são propostas, testadas, aperfeiçoadas e que, quando os resultados são os desejados, acabam sendo adotadas nos mercados. Combine-se esse processo com a globalização e a "importação" de institutos e regras estrangeiros para compreender que Códigos nem sempre são a melhor solução

2 Disponível em: < SSRN.com $>$.

3 Giuffré Ed., 1979. 
para o que se considera a virtude dos direitos da família romano-germano-canônica, que a norma escrita e promulgada confere certeza e segurança às pessoas quando tomam decisões.

Quanto a usos e costumes lembra-se que o Código Comercial, Lei n. 556, 25 de Junho de 1850 , tinha dispositivo prevendo a completude de contratos pelos usos e costumes da praça, isto é, do mercado em que eram celebrados por e entre profissionais, (art. 131). Falta essa regra no Código Civil Brasileiro de 2002 que unificou o direito obrigacional.

Inexistindo regra expressa quanto à interpretação e completamento dos contratos mercantis, notadamente os mais frequentes, os de execução continuada ou diferida, como garantir a confiança dos empreendedores?

Assim, apoiada em Irti e Bernstein, parece-me que normas comerciais programáticas, abertas, quedeixem espaço para quea complexidadedas relações negociais associada à velocidade da inovação, à mudança de preferências dos consumidores, sejam equacionadas mediante práticas socialmente aceitas sem engessamento da criatividade dos agentes econômicos. Regras gerais, informação tão próxima da perfeita quanto possível, fiscalização de alguns setores, tal como faziam as corporações de artes e ofícios, as guildas, parecem mais adequadas, na atual conjuntura. O temor, claro, são arranjos opacos que levem a oligopólios e cartéis causando danos à sociedade. A extração de renda e bem-estar dos consumidores não pode ser admitida.

\section{CONCLUSÃO}

O tráfico de mercadorias, atividade exercida por agentes econômicos que atuavam em diferentes cidades-estados na Idade Média, impunha, para fins de segurança, especialização em face da solução de disputas para dar alguma tranquilidade aos mercadores, notadamente quando se tratava de operações ditas de longa distância, isto é, em países ou cidades-estados afastadas daquele de origem do operador.

Riscos enfrentados com o deslocamento dos bens levou ao aparecimento de garantias, espécie de seguro ao qual faltava a base técnica - cálculo atuarial -.

Fruto da necessidade de redução de custos na negociação massiva de contratos, de que o seguro é um exemplo, visa a reduzir a onerosidade - custos de transação no sentido Coaseano - de tais operações. Por óbvio que cláusulas leoninas são inaceitáveis. $\mathrm{O}$ argumento de que tais contratos padronizados ou por adesão, ferem direitos do consumidor, se aceitas indiscriminadamente, levará ao que os economistas denominam efeitos de segunda ordem, isto é, adoção de práticas visando a contornar a dificuldade ainda que isto imponha custos que, ao final, serão transferidos ao mercado.

Contratos por adesão, prática que visa a facilitar operações maciças dado que a negociação individual implicaria custos muito elevados às duas partes, não devem ser execrados sob o argumento de que faltou "negociação" e isto desequilibra a relação.

Modelos associativos, entre os quais as cooperativas, criados para facilitar a reunião de recursos financeiros destinados a investimentos em atividades econômicas também são contribuição do direito comercial para o exercício de atividades econômicas. 
Entre eles a sociedade em comandita, de origem medieval, é emblemática.

Mas, sobretudo, o Direito Comercial em que relações patrimoniais entre particulares tem como escopo, a voluntária e regular criação e circulação da riqueza, demanda confiança que o sistema gere nas pessoas para que decisões de investimento seja tomadas e com isso se gere bem-estar. A alocação de riscos nas operações comerciais deve ser clara e conhecida, a informação, salvo matérias especiais como segredos de produção, por exemplo, deve ser ampla e completa.

Se Bernstein conclui que a codificação de regras em matéria de contratos comerciais, não é a melhor solução para o desenvolvimento da atividade empresarial, entendo, de minha parte, que a tradição do pátria de preferir regras positivadas, não deve criar óbices para que o exercício da atividade mercantil ou empresarial priorize o formalismo. O engessamento normativo, a aplicação literal das normas jurídicas positivadas, põe em cheque a dinâmica sobre a qual se assentam as instituições sociais que informam o Direito Comercial, mais ligado à economia (e aqui não se cuida de análise econômica do direito, mas sim de direito e economia como dois ramos das ciências sociais aplicadas) do que o direito civil.

Resta saber se o dialogo entre direito e economia preservou os fundamentos informacionais das operações econômicas especializadas, se as cadeias produtivas, fruto da crescente especialização, a robotização e informatização de muitas atividades, estão devidamente recepcionadas nas normas positivadas no Brasil seja no Código Civil Brasileiro seja no projeto de Código Comercial.

A contribuição do Direito Comercial para o desenvolvimento econômico decorre da confiança que o sistema gere para que decisões de investimento ocorram e, com isso, se gere riqueza e bem-estar.

Em suma, para que o Direito Comercial leve ao desenvolvimento econômico mister que a confiança no sistema normativo - tanto normas de direito positivo quanto as socialmente acatadas, não inibam investimentos produtivos. A recepção de novações, as mudanças de mercados, a globalização, fatores inerentes a esse campo do Direito precisam de espaço no quadro normativo para que os efeitos sociais economicamente desejáveis sejam alcançados.

\section{REFERÊNCIAS}

ASCARELLI, Túllio. Problemas das Sociedades Anônimas e Direito Comparado. Quórum. São Paulo: 2008.

BERNSTEIN, Lisa E.. Merchant Law in a Modern Economy Coase-Sandor Institute for Law \& Economics Working Paper No. 639, 2013). Acesso em: o6 nov. 2017.

BOBBIO, Norberto. Da estrutura à função: novos estudos de teoria do direito. Tradução de Daniela Baccaccia Versani. Barueri-SP: Editora Manole, 2007.

NORTH, Douglas. Institutions, Institutional Change and Economic performance, Cambridge University Press, Cambridge, 1990. 
SCHÄFER, Hans-Bernd and WULF, Alexander J., Wie der Aufstieg des gelehrten Rechts im Mittelalter den wirtschaftlichen Aufstieg Europas beförderte. Eine empirische Untersuchung (The Rise of Learned Law in Medieval Europe and Its Impact on Economic Growth) (May 1, 2014). Schäfer/Wulf, Gelehrtes Recht (BLJ), 52, 2014. Available at SSRN: https://ssrn.com/abstract=246266o. Acesso em: o6 nov. 2017.

VIVANTE, CESARE. Instituições de Direito Comercial. São Paulo: Lzn, 2003. 